\title{
EFEITO DO ÁCIDO GIBERÉLICO SOBRE A GERMINAÇÃO DE SEMENTES DE PORTA-ENXERTOS CÍTRICOS ${ }^{1}$
}

\author{
HUMBERTO UMBELINO DE SOUSA ${ }^{2}$, JOSÉ DARLAN RAMOS ${ }^{3}$, \\ MOACIR PASQUAL ${ }^{4}$, ESTER ALICE FERREIRA ${ }^{5}$
}

\begin{abstract}
RESUMO- Com objetivo de avaliar o efeito do ácido giberélico sobre a germinação de sementes de porta-enxertos cítricos, um experimento foi instalado no Laboratório de Cultura de Tecidos da UFLA. Utilizou-se o delineamento de blocos casualizados, com quatro repetições. Os tratamentos foram constituídos a partir do fatorial 5 x 4 (porta-enxertos: Limoeiro- 'Cravo', Tangerineira- 'Sunki', Tangerineira- 'Cleópatra', 'UFLAD-4' e 'UFLAD-5'; ácido giberélico: 0; 60; 120 e $180 \mathrm{mg} \mathrm{L}^{-1}$ ). A parcela experimental foi constituída por 25 tubos de ensaio com uma semente/tubo, empregando-se a água + ágar a $7 \mathrm{mg} \mathrm{L}^{-1}$ como meio de cultura, sendo usadas sementes intactas. Após a inoculação, os tubos foram armazenados em sala sob temperatura de $25^{\circ} \mathrm{Ce} 80 \%$ de umidade relativa, com fotoperíodo de 16 horas. O experimento foi avaliado a partir da determinação da percentagem de germinação, índice de velocidade de germinação (IVG ) e número de plântulas por semente (NPS). O limoeiro- 'Cravo' apresentou maior taxa de germinação e IVG, enquanto o híbrido 'UFLAD-5' apresentou maior NPS, não havendo efeito da aplicação do ácido giberélico sobre as características avaliadas.
\end{abstract}

Termos de indexação- regulador de crescimento; Giberelina, Citrus sp., propagação.

\section{EFFECT OF THE GIBERELLIC ACID ON GERMINATION OF CITRUS ROOTSTOCK SEEDS}

\begin{abstract}
With the aim to evaluate the effect of the giberellic acid on germination of seeds of citrus rootstocks an experiment was carried out at the Tissue Culture Laboratory of Universidade Federal de Lavras. A randomized block design was used with factorial scheme 5 x 4, with four replications adopting: lemon tree 'Cravo', mandarin tree 'Sunki', mandarin tree 'Cleópatra', hybrids 'UFLAD- 4' and 'UFLAD-5' as rootstocks; 0,60,120 and $180 \mathrm{mg} \mathrm{L}^{-1}$ as the giberellic acid concentrations. The experimental plot was made up of 25 test tubes with one intact seed per tube inoculated at culture medium employing water + agar at $7 \mathrm{mg} \mathrm{L}^{-1}$. After inoculation, the tubes were stored in growth room at $25^{\circ} \mathrm{C}$ and $80 \%$ of relative humidity, with a photoperiod of 16 hours. The following variables were evaluated: determination of the germination percentage, speed germination index (IVG) and seedling number per seed (NPS). The analyses showed that lemon tree 'Cravo' presented the better germination rate and speed germination index; the hybrid 'UFLAD-5' presented the highest seedling number per seed, there being no effect of giberellic acid on characteristics evaluated.
\end{abstract}

Index terms - growth regulator, giberellin, Citrus sp. , propagation.

\section{INTRODUÇÃO}

No Brasil, maior produtor mundial de frutos cítricos, aproximadamente $90 \%$ de suas plantas encontram-se apoiadas sobre o porta-enxerto limoeiro- 'Cravo'. Esse fato torna a citricultura brasileira bastante vulnerável, em decorrência do surgimento de doenças, como o declínio dos citros e Clorose Variegada dos Citros (CVC), às quais o limoeiro- 'Cravo' vem apresentando suscetibilidade e, como conseqüência, ocorre a morte de 10 milhões de plantas cítricas anualmente (DERRICK, 1998 ).

Dessa forma, torna-se necessário desenvolver pesquisas com vistas à identificação de novos porta-enxertos, bem como o aprofundamento de estudos com porta-enxertos existentes, com vistas a avaliar seus atributos de qualidade como porta-enxerto. Dentre os porta-enxertos alternativos, destacamse as Tangerineiras- 'Cleópatra' e 'Sunki', o Poncirus trifoliata e os híbridos entre o Limoeiro- 'Cravo' x Poncirus trifoliata, com destaque para 'UFLAD-4' e 'UFLAD-5' (RAMOS, 1990).
Dentro do contexto atual, a utilização de mudas sadias e certificadas vem tornando-se um fator obrigatório, em face da ocorrência de doenças que vêm dizimando os pomares cítricos brasileiros. Dentre as fases de produção da muda cítrica, a produção do porta-enxerto é responsável por cerca de $60 \%$ do tempo demandado. Sendo que, entre os fatores responsáveis por essa demora, encontra-se o período de germinação, que pode chegar a 60 dias ou mais, dependendo do porta-enxerto usado, bem como a desuniformidade entre as plântulas devido à diferença entre o número de dias levados para ocorrer a germinação na sementeira. Esse problema poderá ser minimizado com o emprego de ácido giberélico, que tem a finalidade de acelerar a germinação de sementes e, com isso reduzir o período de germinação, além de uniformizar a germinação na sementeira.

No entanto, pouco se tem pesquisado sobre qual a concentração de ácido giberélico deve ser empregada, nem por quanto tempo as sementes devem permanecer imersas, para que haja uma aceleração no processo de germinação das sementes de citros. Na literatura, existem relatos da aplicação de ácido

1 (Trabalho 119/2001). Recebido: 11/06/2001. Aceito para publicação: 20/12/2001.

2 Pesquisador Embrapa Meio-Norte, Caixa Postal 131, CEP: 65800-000, Balsas, MA. E-mail: humberto@cpamn.embrapa.br

3 Professor Adjunto DAG/UFLA. Caixa Postal 37, CEP: 37200-000, Lavras, MG. E-mail: darlan@ufla.br

4 Professor Titular DAG/UFLA. Caixa Postal 37, CEP: 37200-000, Lavras, MG.

5 Doutoranda em Agronomia/Fitotecnia/UFLA. Caixa Postal 37, 37200-000, Lavras, MG. E-mail: ester@ufla.br

Rev. Bras. Frutic., Jaboticabal - SP, v. 24, n. 2, p. 496-499, agosto 2002 
giberélico sobre sementes de citros com concentrações que atingem $250 \mathrm{mg} \mathrm{L}^{-1}$ e tempo de imersão variando de 0 até 24 horas (CHOUDHARI \& CHAKRAWAR, 1981; ONO et al., 1993; LEONEL et al., 1994a; LEONEL et al., 1994b; RAMOS, $1994 \mathrm{e}$ ONO et al., 1995 ), os quais verificaram efeitos divergentes tanto das concentrações aplicadas quanto do tempo de imersão das sementes no ácido giberélico.

Em função do exposto, o presente trabalho teve como objetivo avaliar o efeito da aplicação de ácido giberélico em diferentes concentrações, sobre a germinação de sementes de porta-enxertos cítricos.

\section{MATERIAL E MÉTODOS}

Utilizaram-se sementes dos porta-enxertos Limoeiro'Cravo'; Tangerineira-'Sunki'; Tangerineira- 'Cleópatra'; 'UFLAD-4' e 'UFLAD-5', pertencentes à coleção de portaenxertos cítricos do Setor de Fruticultura da Universidade Federal de Lavras (UFLA).

As frutas desses porta-enxertos foram colhidas no período de 24 de junho/99 a 19 de julho/99. Após a colheita das frutas, procedeu-se a retirada das sementes. Em seguida, elas foram lavadas em água corrente e, posteriormente, tratadas com $\mathrm{CaOH}$ a $10 \mathrm{~g} \mathrm{~L}^{-1}$ durante cinco minutos para a remoção da mucilagem. Após esse período, as sementes foram lavadas em água corrente e, em seguida, colocadas para secar à sombra sobre papel de jornal durante 72 horas. Após a secagem, elas foram armazenadas em frascos, que foram mantidos à temperatura de \pm $5^{\circ} \mathrm{C}$ e umidade relativa de $\pm 80 \%$, na gaveta de refrigerador, permanecendo por 60 dias.

O experimento foi instalado no laboratório de cultura de tecidos da UFLA. Utilizou-se o delineamento de blocos casualizados, com quatro repetições. Os tratamentos foram constituídos a partir do fatorial 5 x 4 [porta-enxertos: limoeiro- 'Cravo', tangerineira-'Sunki', tangerineira- 'Cleópatra', 'UFLAD-4' e 'UFLAD-5'; ácido giberélico (GA $)$ ): 0; 60; 120 e $180 \mathrm{mg} \mathrm{L}^{-1}$ ]. Como fonte de ácido giberélico, foi usado o produto comercial $\mathrm{GA}_{3}$. A parcela experimental foi constituída por 25 tubos de ensaio com uma semente cada.

Utilizaram-se tubos de ensaio contendo como meio de cultura água + ágar a $7 \mathrm{~g} \mathrm{~L}^{-1}$, colocando-se sementes intactas. Antes da inoculação, as sementes foram envolvidas em uma gaze e imersas em uma solução contendo $\mathrm{GA}_{3}$ nas concentrações preestabelecidas nos tratamentos, permanecendo pelo período de seis horas. Após esse período, foram removidas e colocadas na solução de hipoclorito de sódio a $10 \mathrm{~g} \mathrm{~L}^{-1}$ durante 15 minutos para a assepsia. Após esse período, elas foram levadas para uma câmara de fluxo laminar, removidas do hipoclorito e submetidas a duas lavagens em água destilada autoclavada. Em seguida, procedeu-se a inoculação do tubo de ensaio contendo o meio de cultura água + ágar a $7 \mathrm{~g} \mathrm{~L}^{-1}$, colocando-se uma semente em cada tubo. Após a inoculação, os tubos foram vedados com filme de polietileno e então armazenados em sala de crescimento sob temperatura de $25^{\circ} \mathrm{Ce} 80 \%$ de umidade relativa, com fotoperíodo de 16 horas.

O experimento foi avaliado a partir da determinação da percentagem de germinação, considerando-se o período de até 90 dias pós-inoculação; Índice de Velocidade de Germinação
(IVG), determinado de acordo com POPINIGIS (1977); e número de plântulas por semente (NPS). Durante o período de avaliação, as leituras foram efetuadas com intervalos de três dias.

Os dados foram submetidos à análise de variância, pelo teste F, por intermédio do software Sisvar (FERREIRA, 2000), sem sofrer transformação. Para as características significativas, aplicou-se o teste de Scott-Knott para a comparação entre as médias dos tratamentos.

\section{RESULTADOS E DISCUSSÃO}

Não se constataram efeitos significativos da aplicação do ácido giberélico sobre as características avaliadas $(\mathrm{P}>0,05)$. No entanto, verificaram-se diferenças significativas $(\mathrm{P}<0,05)$ entre os porta-enxertos, em todas as características avaliadas (Tabela 1).

Para o resultado observado em relação ao ácido giberélico, o fato é atribuído a um adequado nível endógeno de giberelina nas sementes, de forma que a adição do $\mathrm{GA}_{3}$ não interferiu em sua performance durante a germinação. Resultados semelhantes foram constatados nas pesquisas de LEONEL $e$ t al. (1994a) e LEONEL et al. (1994b), com o emprego de concentrações de ácido giberélico que variaram de 0 a $250 \mathrm{mg} \mathrm{L}^{-1}$ e tempo de imersão de 24 horas sobre a germinação de sementes de Citrus amblycarpa e Laranja-Azeda, respectivamente. Entretanto, ONO et al. (1993) constataram inibição da germinação de sementes de Citrus volkameriana quando empregaram ácido giberélico na concentração de $250 \mathrm{mg} \mathrm{L}^{-1}$ e tempo de imersão de 24 horas, enquanto a aplicação de $50 \mathrm{mg} \mathrm{L}^{-1}$ de $\mathrm{GA}_{4}+\mathrm{GA}_{7}+$ fenilmetilaminopurina proporcionou $89 \%$ de sementes germinadas em 22,29 dias, superando os demais tratamentos. Resultados positivos da aplicação de fitorreguladores sobre o tempo médio para germinação e velocidade média de germinação de sementes de Citrumelo-Swingle também foram detectados com a aplicação de $\mathrm{GA}_{3}$ a $50 \mathrm{mg} \mathrm{L}^{-1}$ e tempo de imersão de 24 horas (ONO et al., 1995). Além desses relatos, destacam-se os resultados constatados por RAMOS (1994), onde se verificou um efeito linear da aplicação de ácido giberélico até a concentração $100 \mathrm{mg} \mathrm{L}^{-1} \mathrm{e}$ tempo de imersão das sementes por seis horas, porém trabalhando com sementes de tangerina-'Sunki'.

Quanto aos diferentes porta-enxertos, constatou-se que os porta-enxertos limão- 'Cravo' e tangerina- 'Sunki' apresentaram maiores taxas de germinação, enquanto os híbridos 'UFLAD-5' e 'UFLAD-4' foram os que apresentaram menores valores (Tabela 2).

Performance superior na taxa de germinação do limoeiro- 'Cravo' e da tangerina- 'Sunki' também foram constatadas por SOARES FILHO et al. (1995) e RAMOS et al.(1991). Quanto à performance inferior na germinação das sementes híbridas, o fato pode ser atribuído ao fator genético, visto que o Poncirus trifoliata e seus híbridos geralmente apresentam menores taxas de germinação quando comparado às demais espécies cítricas, conforme também constatado por BUTTON et al. (1971) e RAMOS et al. (1991).

Para a caraterística Índice de Velocidade de Emergência (IVG), constatou-se que o Limoeiro- 'Cravo' foi o porta-enxerto que apresentou maior IVG, enquanto o híbrido 'UFLAD-5' foi o que apresentou menor valor (Tabela 2). A partir dos valores 
Tabela 1- Resumo da análise de variância.

\begin{tabular}{|c|c|c|c|}
\hline \multirow[t]{2}{*}{ Fonte de variação } & \multicolumn{3}{|c|}{ QM } \\
\hline & \%germinação & IVG & NPS \\
\hline Porta-enxerto & $17308,5280 * *$ & $1,74883 * *$ & $0,62464 * *$ \\
\hline GA 3 & $18,76467 \mathbf{n s}$ & $0,00560 \mathbf{n s}$ & $0,01577 \mathbf{n s}$ \\
\hline Porta-enxerto x GA3 & $162,168 \mathbf{n s}$ & $0,01385 \mathbf{n s}$ & $0,05562 \mathbf{n s}$ \\
\hline Bloco & $178,35433 \mathbf{n s}$ & $0,10264 \mathbf{n s}$ & $0,01507 \mathbf{n s}$ \\
\hline Resíduo & 159,16275 & 0,02140 & 0,03043 \\
\hline
\end{tabular}

**- significativo pelo teste $\mathrm{F}$ a $1 \%$ de probabilidade; ns- não significativo pelo teste $\mathrm{F}$ a $5 \%$ de probabilidade.

Tabela 2- Valores médios de germinação, Índice de Velocidade de Germinação (IVG) e Número de Plântulas por Semente (NPS) de portaenxertos cítricos.

\begin{tabular}{lcccc}
\hline Porta-Enxerto & \multicolumn{3}{c}{ Característica* } \\
\cline { 2 - 5 } \cline { 3 - 5 } & Germinação (\%) & IVG & NPS \\
\hline Tangerineira-'Sunki' & $92,80 \mathrm{a}$ & $0,804 \mathrm{~b}$ & $1,145 \mathrm{~b}$ \\
Tangerineira-'Cleópatra' & $77,50 \mathrm{~b}$ & $0,515 \mathrm{c}$ & $1,204 \mathrm{~b}$ \\
Limoeiro-'Cravo' & $96,45 \mathrm{a}$ & $0,933 \mathrm{a}$ & $1,116 \mathrm{~b}$ \\
'UFLAD-4' & $45,00 \mathrm{c}$ & $0,300 \mathrm{~d}$ & $0,996 \mathrm{c}$ \\
'UFLAD-5' & $20,08 \mathrm{~d}$ & $0,146 \mathrm{e}$ & $1,523 \mathrm{a}$ \\
\hline
\end{tabular}

*- médias seguidas de mesma letra não diferem estatisticamente entre si, pelo teste de Scott \& Knott, a 5\% de probabilidade.

observados na Tabela 2, pode-se inferir que as sementes dos limão- 'Cravo' apresentam maior vigor que as sementes do demais porta-enxertos, o que provavelmente possibilitará uma redução no tempo de produção do porta-enxerto. Porém, os valores observados para as sementes da tangerineira-'Sunki' mostram-se um material com um bom potencial, pois o índice de velocidade de germinação foi inferior apenas ao apresentado pelas sementes do limoeiro- 'Cravo', embora com valores relativamente próximos, o que indica que a semente deste material apresenta uma maior desuniformidade de germinação que as do limoeiro'Cravo'.

Para a característica número de plântulas por semente (NPS), verificou-se que o híbrido 'UFLAD-5' foi o porta-enxerto que apresentou maior NPS, apresentando uma média de 1,52 plântula/semente, contra 1,14 plântula/semente da tangerina'Sunki' ; 1,20 plântula/semente da tangerina- 'Cleópatra'; 1,12 plântula/semente do limão- 'Cravo', e 0,99 plântula/semente do 'UFLAD-4' (Tabela 2). Esse resultado constatado é inferior aos relatos existentes na literatura, os quais indicam um número de 1,72 e 1,06 plântula/semente de tangerina- 'Sunki' (RAMOS, 1994 e SOARES et al., 1995); 1,41 e 1,15 plântula/semente de limão'Cravo' (RAMOS, 1990 e SOARES et al., 1995); e 2,39 plântula/ semente no híbrido entre limão- 'Cravo' e Poncirus trifoliata (RAMOS, 1990 ). A divergência verificada pode ser atribuída ao fato de que o número de embriões contido em uma semente pode ser influenciado pela cultivar, estado nutricional do fruto, fatores ambientais e cultivar polinizadora (FROST \& SOOST, $1968 \mathrm{e}$ OGAT et al., 1981).

\section{CONCLUSÕES}

1 - As sementes dos porta-enxertos limoeiro- 'Cravo' e tangerineira-'Sunki' apresentaram maior taxa de germinação, fato bastante relevante para a indicação de um porta-enxerto, porém as sementes de limoeiro- 'Cravo' apresentaram maior vigor.

2 - O porta-enxerto 'UFLAD-5' apresenta maior número de plântulas por semente.
3 - O ácido giberélico não influenciou a germinação de sementes dos porta-enxertos cítricos estudados, de forma que não se recomenda a aplicação deste produto no processo de formação de mudas.

\section{REFERÊNCIAS BIBLIOGRÁFICAS}

BUTTON, J.; BORMAN, C. h.; HACKLAND, B.A. Effect of presowing treatment on the germination of Poncirus trifoliata and troyer citrange seeds. Citrus and subtropical fruit journal, Schagn, V. 451, p. 9-11, 1971.

CHOUDHARI, B. K.; CHAKRAWAR, V. R. Note on the effect of some chemicals in the germination of rangpur lime seeds. Indiam journal agricultural Sciences, New Delhi, v. 51, n. 3, p. 201-203, mar. 1981.

DERRICK, K. S. Evidências indicam que o declínio dos citros é uma doença infecciosa. Laranja, Cordeirópolis, V. 19, n. 1, p. 107-116, 1998.

FERREIRA, D. F. Sisvar- Sistema de análise estatística para dados balanceados. Lavras: DCE-UFLA, 2000. CD-ROM.

FROST, H. B.; SOOST, R. K. Seed reproduction development of gamets and embryos. In: REUTHER, W.; BATCHELOR, L. D.; WEBBER, H. J. The Citrus Industry. Berkeley: University of California Press, 1968. v.2, cap. 4, p.290-324.

LEONEL, S.; MODESTO, J. C.; RODRIGUES, J. D. Influência de fitorreguladores e nitrato de potássio na germinação de sementes e no crescimento de porta-enxerto de Citrus amblycarpa. Scientia Agrícola, Piracicaba, v. 51, n. 2, p. 252-259, maio/ago., 1994a.

LEONEL, S.; ONO, E. O.; RODRIGUES, J. D. Ação de giberelinas e citocininas na germinação de sementes de laranja Azeda. Re-

Rev. Bras. Frutic., Jaboticabal - SP, v. 24, n. 2, p. 496-499, agosto 2002 
vista de Agricultura, Piracicaba, v. 69, n. 2, p. 201-211, setembro, 1994b.

OGATA, T.; SOUZA, M. de; SANTOS, M. G. F. M. Poliembrionia, efeitos do nitrato de potássio e da permanência de sementes no germinador na separação de embriões de citros. In: CONGRESSO BRASILEIRO DE FRUTICULTURA, 6., 1981, Recife. Anais...Recife: SBF, 1981.v.2, p.693-701.

ONO, E.O.; LEONEL, S. RODRIGUES, J. D. Efeitos de fitorreguladores e nitrato de potássio na germinação de sementes do limão 'Volkameriano'. Scientia agrícola, Piracicaba, v. 50, n. 3, p. 338-342, out./dez., 1993.

ONO, E.O.; LEONEL, S. RODRIGUES, J. D. Efeitos de fitorreguladores na germinação de sementes de citrumelo 'Swingle'. Semina, Londrina, v. 16, n. 1, p. 47-50, março, 1995.

POPINIGIS, F. Fisiologia da semente. Brasília: AGIPLAN/BID, 1977. 288p.

RAMOS, J. D. Caracterização fenotípica do fruto, micropropagação e germinação de sementes do porta-enxerto tangerina 'Sunki' (Citrus sunki Hort. Ex. Tan.). 1994. 85f. Tese (Doutorado em Fitotecnia) - Escola Superior de Agricultura de Lavras, Lavras, 1994.

RAMOS, J. D. Taxa de poliembrionia e identificação do embrião sexual "in vitro" dos porta-enxertos Citrus limonia Osbeck cv. Cravo e Poncirus trifoliata (L.) RAF. 1990. 73f. Dissertação (Mestrado em Genética e Melhoramentos de plantas) - Escola Superior de Agricultura de Lavras, Lavras, 1990.

RAMOS, J. D.; CARVALHO, S. A. de; PASQUAL, M. Efeito da extração do tegumento na expressão da poliembrionia de dois porta-enxertos cítricos. Revista Brasileira de Fruticultura, Cruz das Almas, v. 13, n. 1, p. 161-166, out. 1991.

SOARES FILHO, W. dos S.; PELACANI, C. R.; SILVA SOUZA, A. da; CUNHA SOBRINHO, A. P. da; ARAÚJO, E. F. de. Influência dos tegumentos externos e interno na germinação de sementes de citros: Implicação na sobrevivência de "seedlings" híbridos. Revista Brasileira de Fruticultura, Cruz das Almas, v. 17, n. 1, p. 91-101, nov. 1995. 